\title{
Analisis Video Likes to Likes Ratio TikTok Pada 5 Merek Laptop Terbaik Tahun 2021
}

\author{
Anak Agung Prasma Indra Mahendra \\ Prasmaindra.pi@gmail.com
}

\begin{abstract}
During this pandemic period where as we know activities in the form of physical contact have begun to be prohibited, therefore many people are looking for entertainment on social media.One of the popular social media today is Tiktok, TikTok is a social media application launched by the company from China. TikTok allows users to create 15 -second videos accompanied by music, filters, and several other creative features. Currently, TikTok users have reached more than 1 billion. Seeing the rapid development of this application, the famous Laptop Brand has made the TikTok platform a social one. marketing media. The purpose of this study is to calculate the credibility of the TikTok account performance of the 5 Best Laptop Brands in 2021. The method used for this research is a quantitative exploratory method. The results of this study indicate that the Lenovo Laptop Brand is ranked first and has good account performance credibility.
\end{abstract}

\begin{abstract}
ABSTRAK
Selama masa pandemi ini dimana seperti yang kita ketahui kegiatan dalam bentuk kontak fisik sudah mulai dilarang,oleh karena itu banyak masyarakat yang mencari hiburan di Media social.Salah satu media sosial yang populer saat ini adalah Tiktok, TikTok merupakan aplikasi sosial media yang diluncurkan oleh perusahaan asal Tiongkok. TikTok memungkinkan penggunanya membuat video berdurasi 15 detik yang disertai dengan musik, filter, dan beberapa fitur kreatif lainnya.Saat ini pengguna Tiktok telah mencapai lebih dari 1 miliar.Melihat perkembangan aplikasi ini yang sangat cepat,membuat Brand dari Laptop terkenal menjadikan platform TikTok sebagai social media marketing. Tujuan dari penelitian ini yaitu untuk menghitung kredibilitas dari performa akun TikTok 5 Merek Laptop Terbaik Tahun 2021. Metode yang digunakan untuk penelitian ini yaitu metode eksploratif kuantitatif. Hasil dari penelitian ini menunjukan bahwa Merk Laptop Lenovo mendapatkan peringkat pertama dan memiliki kredibilitas performa akun yang baik.
\end{abstract}

Keyword : Pandemic ; Social Media Tiktok ; Social Media Marketing ; Video Likes To Likes Ratio ; Credibility TikTok Account ; Merk Laptop Terbaik Tahun 2021 


\section{PENDAHULUAN}

Seiring dengan kemajuan tekhnologi, maka banyaknya media yang dapat digunakan manusia untuk dijadikan alat dalam berkomunikasi, demikian pula dengan media sosial yang dapat dengan mudah diakses melalui jaringan internet. Pada umumnya fungsi dari media sosial diantaranya untuk berbagi pesan dengan banyak pengguna media sosial itu sendiri,yaitu berupa berita (informasi), gambar (foto) dan juga tautan video. Media sosial tidak hanya dapat di akses di perangkat komputer, tetapi dengan adanya aplikasi di smartphone atau telepon pintar, maka semakin memudahkan masyarakat untuk mengakses media sosial secara mobile sehingga dapat diakses kapanpun dan di manapun.

Perkembangan media sosial ini membuat remaja sendiri mulanya berlomba-lomba dalam membina komunitas melalui jaringan internet terutama media sosial yang terdiri dari Facebook, Twitter, YouTube, Tiktok, Instagram, WhatsApp, Game Online dan masih banyak lagi. Dalam perkembangan teknologi sekarang, salah satu media sosial yang paling menonjol yang sangat populer di kalangan anak- anak maupun remaja dan mahasiswa adalah media social TikTok.

TikTok atau yang dikenal sebagai aplikasi sinkron bibir (lip-sync) saat ini sedang berada di atas puncak ketenarannya. Media sosial berbasis video ini mendapat banyak perhatian dari masyarakat, terutama pada generasi muda. Zhang Yiming adalah tokoh dibalik peluncuran platform video musik 7 tersebut. Beliau merupakan alumni dari Universitas Nankai lulusan software engineer. Selain menjadi alumni dari Universitas Nankai, ia juga mendirikan perusahaan teknologi yang disebut "ByteDance". Dari proses itu kemudian terciptalah media sosial TikTok yang merupakan media pembuat video berdurasi pendek. (www.moneysmart.id 04/07/2018)

Dengan perkembangan Tiktok yang sangat cepat dan saat ini mencapai lebih dari 1 miliar pengguna,membuat Brand dari Laptop terkenal untuk menjadikan platform ini sebagai platform social media marketing. Penelitian ini menggunakan metode eksploratif kuantitatif, dan akan menghitung menggunakan rasio-rasio yang ada pada TikTok. Pada penelitian (Permana and Meinarni 2021) menjelaskan bahwa terdapat 17 rasio yang ada pada sosial media TikTok dan relevan digunakan sebagai media ukur kredibilitas akun yang ada. Penelitian ini hanya berfokus untuk menghitung kredibilitas Video Likes To Likes Ratio pada 5 Merk Laptop Terbaik Tahun 2021. Adapun 5 Merk Laptop Terbaik Tahun 2021, diantaranya yaitu : Dell,HP,Apple,Asus,Lenovo (“5 Merek Laptop Terbaik Tahun 2021- katadata.id”13 Agustus) Tujuan dari penelitian ini adalah mengetahui kredibilitas performa dari akun TikTok 5 Merek Laptop Terbaik Tahun 2021.

\section{TINJAUAN PUSTAKA}

Penelitian ini terinspirasi dari karya Khoiriyati dan Saripah (2018) tentang manfaat media sosial sebagai pembawa perubahan baik pada kepribadian,kreatifitas,sosialisasi,kecerdasan dan lainnya.Untuk dunia,media sosial juga sangat bermanfaat dikarenakan dapat mendekatkan yang jauh dan juga memiliki beberapa manfaat bagi sebagian kalangan tertentu.Tidak lagi sebagai media 
untuk penyampai pesan kepada yang jauh,media sosial kini telah menjelma menjadi media untuk hiburan,bersosialisasi,menentukan lifestyle, media untuk bisnis sampai media pendidikan.

Penelitian ini terinspirasi dari karya Michael Hartono (2019) tentang aplikasi social video pendek ini (TikTok) yang dapat membantu para user untuk bisa menjadi content creator ,dikarenakan aplikasi ini memiliki dukungan musik yang banyak sehingga penggunanya dapat melakukan performanya dengan tarian,gaya bebas,yang dapat mendorong kreativitas penggunanya

Aplikasi TikTok juga dapat dijadikan peluang bagi brand atau perusahaan sebagai platform social media marketing. Penelitian (Purnamasari and Tutiasri 2021) menyatakan bahwa TikTok berpengaruh positif dan signifikan terhadap minat beli atau berbelanja secara online. Sehingga dengan ini, TikTok mampu memberikan peluang yang sangat tinggi bagi perusahaan-perusahaan dalam melakukan digital marketing.

TikTok dirasakan memiliki kekuatan ataupun pengaruh dalam industri, sehingga menimbulkan kualitas akun yang menentukan strata maupun kredibilitas pemilik akun. Kredibilitas akun TikTok merupakan suatu hal yang cukup penting untuk berbagai kepentingan. Kredibilitas sebuah akun TikTok dapat diukur dari tingkat performa yang dihasilkan secara matematis. Dalam mengukur performa diperlukan skala pengukuran yang tertuang ke dalam rasio.

\section{METODE PENELITIAN}

Penelitian ini menggunakan metode eksploratif kuantitatif untuk mengetahui kredibilitas dari performa akun TikTok 5 Merek Laptop Terbaik Tahun 2021.Metode eksploratif merupakan penelitian yang memiliki tujuan untuk melakukan eksplorasi atau memperdalam pengetahuan ataupun ide-ide baru mengenai suatu hal yang baru, guna merumuskan permasalahan secara terperinci (Maryam, Isrok'atun, and Aeni 2016) .

Tujuan dari penelitian ini yaitu mengetahui nilai kredibillitas dari performa akun TikTok 5 Merk Laptop Terbaik Tahun 2021. Ada beberapa langkah yang harus dilakukan dalam penelitian ini, sehingga mampu menemukan peringkat pertama akun TikTok Laptop Terbaik Tahun 2021 yang memiliki performa terbaik. Langkah-langkah yang dilakukan pada penelitian ini,diantaranya yaitu :

\section{Melakukan Eksplorasi Pada Website Untuk Menentukan Objek yang Akan Dianalisa.}

Eksplorasi ini dilakukan pada beberapa halaman website yang menyediakan informasi mengenai objek yang akan di teliti. Setelah ekpslorasi selesai dilakukan, sehingga ditemukan nama-nama Merk Laptop Terbaik Tahun 2021yang akan dijadikan objek analisa. Setelah melakukan eksplorasi pada halaman website, maka langkah selanjutnya yaitu mencari nama akun TikTok dari masing-masing Merk Laptop.

2. Menghitung Nilai Rata-Rata Variable Dari 5 Merek Laptop Terbaik Tahun 2021. Pada langkah ini, peneliti menghitung nilai variable video likes dan variable likes .Variabel merupakan sesuatu yang memiliki nilai bervariasi dimana nilai tersebut dapat dijadikan sebagai dasar untuk empat data yang berbeda seperti rasio, skala, 
ordinal, nominal dan internal (Rankuti 2015).Untuk menghitung nilai rata-rata dari variabel video likes dan variabel likes yaitu dengan cara mengambil minimal 10 postingan kemudian di hitung sehingga menemukan nilai rata-rata dari masing-masing variabel.

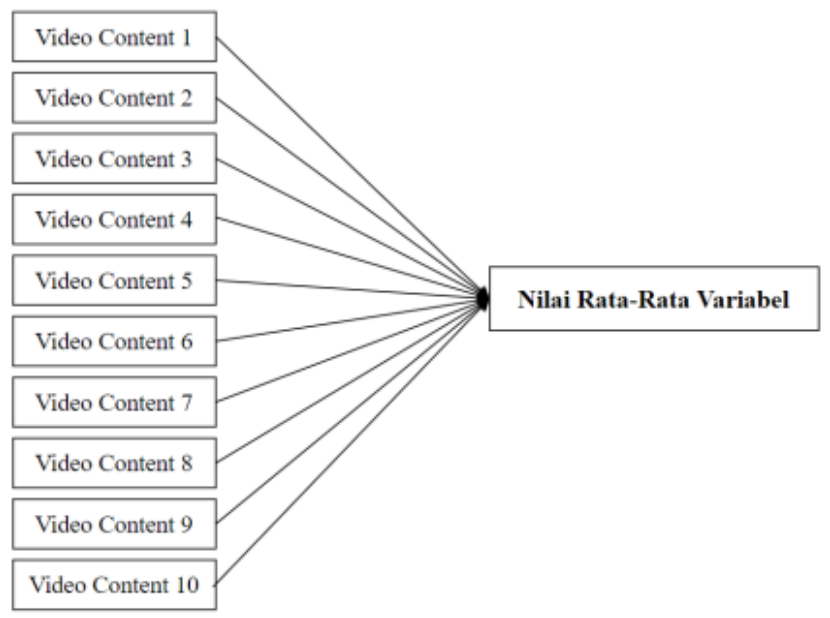

Gambar 1. Analisa Nilai Rata - rata variable

\section{Menghitung Nilai Kredibilitas Rasio}

Untuk menghitung nilai kredibilitas dari video likes to likes, peneliti menggunakan cara membagi nilai variabel pertama dengan nilai variabel kedua. Jika video likes memiliki nilai 100 dan likes memiliki nilai 300, maka cara menghitungnya yaitu $100: 300=0,3$. Dengan begitu nilai dari video likes to likes ratio adalah 0,3 .

\section{Menentukan Peringkat Pada Akun TikTok}

Pada penentuan peringkat perlu melihat karakteristik dari rasio yang di teliti. Jika karakteristik rasio merupakan rendah, maka objek yang memiliki nilai terendah akan mendapatkan angka 1 dan objek yang memiliki nilai tertinggi akan mendapatkan angka 5. Namun jika rasio memiliki karakteritik tinggi maka objek yang mendapatkan nilai tinggi akan mendapatkan angka 1 dan objek yang mendapatkan nilai terendah akan mendapatkan angka 5.Setelah mendapatkan hasil kredibilitas ratio maka dapat disimpulkan objek yang mana mendapatkan peringkat 1 sampai dengan peringkat 5 . 


\section{HASIL DAN PEMBAHASAN}

Akun TikTok dari 5 Merek Laptop Terbaik Tahun 2021,diantaranya :

1. Dell ( Tidak Memiliki Akun Tiktok )

2. HP

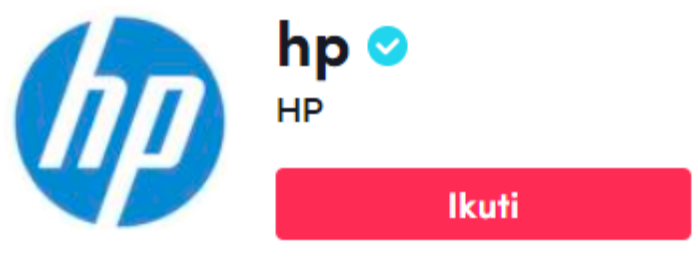

13 Mengikuti 77.3K Pengikut 913.2K Suka

Show us how you reuse ocean-bound plastic in radical ways using \#HPRadicalReuse

$\mathcal{H}$ H.com/hp-sustainability

Gambar 1.Akun Tiktok HP

Sumber : https://www.tiktok.com/@hp

\section{Apple}

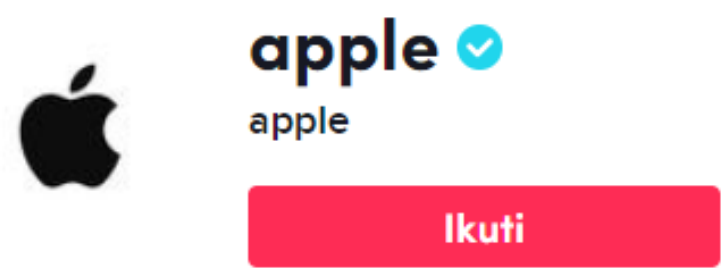

0 Mengikuti $1 \mathrm{M}$ Pengikut 4.4M Suka

Lights, camera, action.

\#MakeltCinematic

Gambar 2.Akun Tiktok Apple

Sumber : https://www.tiktok.com/@apple 
5. Asus

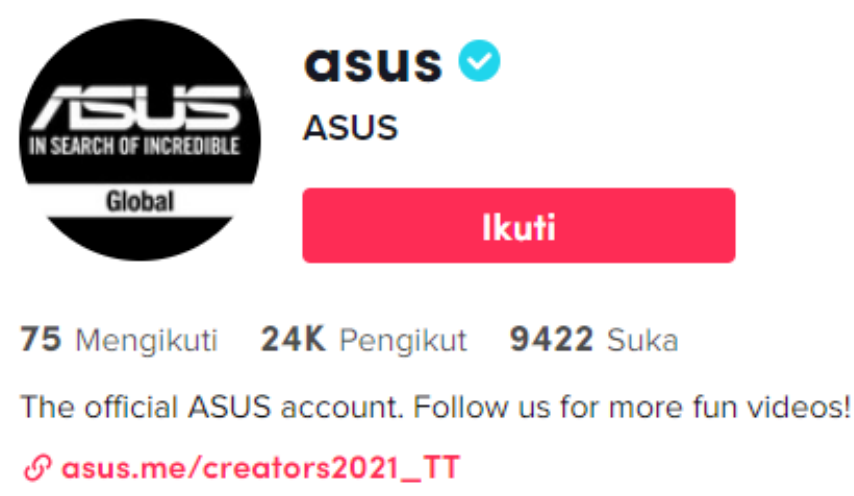

Gambar 3.Akun Tiktok Asus

Sumber : https://www.tiktok.com/@asus

\title{
6. Lenovo
}

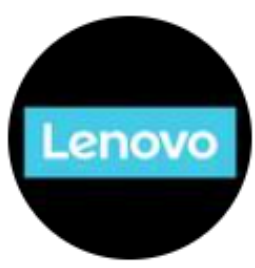

lenovo

Lenovo

\section{Ikuti}

\begin{abstract}
0 Mengikuti 624K Pengikut 11.3M Suka
Create, tweak, improve, defy. Smarter technology for all.

$\mathcal{~ w w w . l e n o v o . c o m ~}$
\end{abstract}

Gambar 4.Akun Tiktok Lenovo

Sumber : https://www.tiktok.com/@lenovo

Dari kelima akun TikTok 5 Merek Laptop Terbaik Tahun 2021, peneliti menemukan nilai dari masing-masing variabel yang ada untuk menghitung rasio Video Likes to Likes dari setiap akun. Pada akun TikTok terdapat 7 variabel,diantaranya yaitu :

1. Likes

2. Followers

3. Following

4. Video Likes

5. Video Comments

6. Video Share

7. Video Views

Dari ketujuh variabel tersebut peneliti hanya fokus untuk menemukan hasil dari 2 variabel,yaitu :

1. Video Comments

2. Video Views 
Dari kedua variabel tersebut kemudian dianalisa sehingga menemukan nilai rata-rata dari variabel video likes dan variabel likes.Untuk menghitung nilai rata-rata dari variabel video likes dan variabel likes yaitu dengan cara melihat minimal 10 postingan kemudian di hitung sehingga menemukan nilai rata-rata dari masing-masing variabel. Berikut merupakan tabel nilai rata-rata dari masing-masing merk laptop, yaitu :

Tabel 1. Analisa Nilai Rata - Rata Nilai Variabel Video Likes dan Likes Akun HP

\begin{tabular}{|c|r|l|}
\hline No & \multicolumn{1}{|c|}{ Video Likes } & Likes \\
\hline 1 & 488 & \\
\hline 2 & 295 & \\
\hline 3 & 183 & \\
\hline 4 & 222 & \\
\hline 5 & 254 & \\
\hline 6 & 526.500 & \\
\hline 7 & 29.700 & \\
\hline 8 & 46.900 & \\
\hline 9 & 92.000 & \\
\hline 10 & 115.700 & \\
\hline Total & 81.224 & 913.200 \\
\hline
\end{tabular}

Sumber : Pengolah Data Exceel

Tabel 2. Analisa Nilai Rata - Rata Nilai Variabel Video Likes dan Likes Akun Apple

\begin{tabular}{|c|r|l|}
\hline No & Video Likes & Likes \\
\hline 1 & 34.200 & \\
\hline 2 & 101.900 & \\
\hline 3 & 20.000 & \\
\hline 4 & 24.800 & \\
\hline 5 & 24.400 & \\
\hline 6 & 43.500 & \\
\hline 7 & 383.800 & \\
\hline 8 & 297.100 & \\
\hline 9 & 525.700 & \\
\hline 10 & 422.700 & \\
\hline Total & 187.810 & 4.400 .000 \\
\hline
\end{tabular}

Sumber : Pengolah Data Exceel 
Tabel 3. Analisa Nilai Rata - Rata Nilai Variabel Video Likes dan Likes Akun Asus

\begin{tabular}{|c|c|c|}
\hline No & Video Likes & Likes \\
\hline 1 & 30 & \\
\hline 2 & 45 & \\
\hline 3 & 51 & \\
\hline 4 & 59 & \\
\hline 5 & 50 & \\
\hline 6 & 51 & \\
\hline 7 & 45 & \\
\hline 8 & 54 & \\
\hline 9 & 84 & \\
\hline 10 & 44 & \\
\hline Total & 51 & 9422 \\
\hline
\end{tabular}

Sumber : Pengolah Data Exceel

Tabel 4. Analisa Nilai Rata - Rata Nilai Variabel Video Likes dan Likes Akun Lenovo

\begin{tabular}{|c|r|l|}
\hline No & \multicolumn{1}{|c|}{ Video Likes } & \multicolumn{1}{c|}{ Likes } \\
\hline 1 & 87 & \\
\hline 2 & 577 & \\
\hline 3 & 1.580 & \\
\hline 4 & 400 & \\
\hline 5 & 156 & \\
\hline 6 & 132 & \\
\hline 7 & 652 & \\
\hline 8 & 13.100 & \\
\hline 9 & 2.182 & \\
\hline 10 & 19.800 & \\
\hline Total & 3.867 & 11.300 .000 \\
\hline
\end{tabular}

Sumber : Pengolah Data Exceel

Setelah menghitung nilai rata-rata tersebut, maka akan menemukan hasil akhir nilai rata-rata dari variabel video likes dan Likes

Tabel 5. Nilai Variabel Pada Akun TikTok 5 Merk Laptop Terbaik Tahun 2021

\begin{tabular}{|l|l|l|l|l|}
\hline Variabel & HP & Apple & \multicolumn{1}{l|}{ Asus } & \multicolumn{1}{l|}{ Lenovo } \\
\hline Video Likes & 81.224 & 187.810 & 51 & 3.867 \\
\hline Likes & 913.200 & 4.400 .000 & 9.422 & 11.300 .000 \\
\hline
\end{tabular}

Sumber : Pengolah Data Exceel

Ada 7 Variabel di TikTok yang digunakan untuk mengukur kredibilitas tapi pada penelitian kali ini hanya berfokus untuk menghitung 2 Variabel yaitu Video Likes to Likes Ratio dari masingmasing akun TikTok setiap merk laptop. 
Cara menghitung nya adalah : variabel 1 akan dibagi dengan variabel 2, sehingga ditemukan hasil analisisa dari rasio tersebut.

Tabel 6. Hasil Perhitungan Rasio Akun TikTok

\begin{tabular}{|l|l|l|l|l|}
\hline Ratio & HP & Apple & Asus & Lenovo \\
\hline Video Likes To Likes Ratio & 0,08894437 & 0,04268409 & 0,00541286 & 3,4221239 \\
\hline \multicolumn{4}{|c|}{ Sumber : Pengolah Data Exceel }
\end{tabular}

Video Likes to Likes Ratio memiliki karakteristik yang tinggi, artinya semakin tinggi nilai yang dihasilkan maka semakin baik kredibilitas dari performa akun tersebut. Untuk memberikan peringkat pada masing-masing Merk Laptop, peneliti memberikan angka 1 kepada merk yang mendapatkan nilai tertinggi dan angka 4 untuk Merk Laptop yang mendapatkan nilai terendah.

Berikut merupakan tabel urutan nilai yang dihasilkan oleh masing-masing Merk Laptop

Tabel 7. Nilai Rasio Akun TikTok 5 Merk Laptop Terbaik Tahun 2021

\begin{tabular}{|c|c|c|c|c|}
\hline \multicolumn{1}{|c}{ Ratio } & Nilai & Nilai2 & Nilai3 & Nilai4 \\
\hline & HP & Apple & Asus & Lenovo \\
\hline Video Likes To Likes & 2 & 3 & 4 & 1 \\
\hline
\end{tabular}

Sumber : Pengolah Data Exceel

Dari Tabel Nilai Rasio Akun TikTok 5 Merk Laptop Terbaik Tahun 2021 dapat simpulkan bahwa Lenovo mendapatkan nilai tertinggi untuk rasio Video Likes To Likes. Sedangkan akun TikTok Asus mendapatkan nilai terendah untuk rasio ini. Jadi, pada penelitian ini Lenovo memiliki kredibilitas performa yang lebih baik dibandingkan dengan Merk Laptop yang lainnya.

\section{KESIMPULAN}

Tujuan dari penelitian ini adalah mengetahui kredibilitas performa dari akun TikTok 5 Merek Laptop Terbaik Tahun 2021 menggunakan Video Likes to Likes Ratio. 5 Merek Laptop Terbaik Tahun 2021tersebut diantaranya :Dell,HP,Apple,Asus,Lenovo Dari kelima Merek Laptop tersebut dapat disimpulkan bahwa :

1. Peringkat Pertama diraih oleh Merek Laptop Lenovo dengan nilai 3,4221239

2. Peringkat Kedua diraih oleh Merek Laptop HP dengan nilai 0,08894437

3. Peringkat Ketiga diraih oleh Merek Laptop Apple dengan nilai 0,04268409

4. Peringkat Keempat diraih oleh Merek Laptop Asus dengan nilai 0,00541286

Dan untuk Merek Laptop Dell tidak masuk peringkat dikarenakan tidak memiliki akun Tiktok 


\section{DAFTAR PUSTAKA}

5 Merek Laptop Terbaik Tahun 2021 - Teknologi Katadata.co.id. (n.d.). Retrieved December 4, 2021, from https://katadata.co.id/intannirmala/digital/6115d82a65067/5-merek-laptop-terbaiktahun-2021

Cerita di Balik Sukses Zhang Yiming, Sang Pendiri Tik Tok|MoneySmart.id|LINE TODAY. (n.d.). Retrieved December 4, 2021, from https://today.line.me/id/v2/article/eEQ0Zg

Bulele, Y. N., \& Wibowo, T. (n.d.). ANALISIS FENOMENA SOSIAL MEDIA DAN KAUM MILENIAL: STUDI KASUS TIKTOK (Vol. 1). http://journal.uib.ac.id/index.php/cbssit

Akademi Komunikasi BSI Jakarta, S. (2018). Pemanfaatan Aplikasi Tiktok Sebagai Personal Branding Di Instagram (Studi Deskriptif Kualitatif Pada Akun @bowo_allpennliebe). Jurnal Komunikasi, 9(2), 176-185. http://ejournal.bsi.ac.id/ejurnal/index.php/jkom

Nora Usrina, 160401033, FDK, KPI, 082249503527. (n.d.).

Oktaheriyani, D., Wafa, M. A., \& Shadiqien, S. (n.d.). ANALISIS PERILAKU KOMUNIKASI PENGGUNA MEDIA SOSIAL TIKTOK (Studi Pada Mahasiswa Fakultas Ilmu Sosial dan Ilmu Politik UNISKA MAB Banjarmasin).

Permana, I. Putu Hendika, and Ni Putu Suci Meinarni. "Ratio Analysis on Tiktok (Social Media) for Qualitative Research Using Explorative Methods." Jurnal Ekonomi \& Bisnis JAGADITHA 8.1 (2021): 3038. 